\title{
O passado subtraído da desaparição forçada: Araguaia como palimpsesto
}

\author{
Roberto Vecchi ${ }^{1}$ \\ Deixaram de existir mas o existido \\ continua a doer eternamente. \\ Carlos Drummond de Andrade
}

Araguaia, hoje, não é só mais uma página em branco da história (ainda largamente por escrever) da ditadura militar no Brasil (19641985). ${ }^{2}$ É, em simultâneo, o mais espectral e, por paradoxo, se diria, o mais contemporâneo dos seus silêncios, das suas narrativas lacunosas e dispersas.

O que aconteceu naquela região do "Brasil ignoto" (para assumir uma definição clássica que remonta ao contexto encoberto de outro massacre, mais uma vez por parte do Estado republicano, aquele de Canudos em finais do século XIX na Bahia) sempre mais parece se constituir a partir da sua força de paradigma interpretativo mais amplo, sem com isso pretender transfigurar um caso trágico em um exemplo iluminador de uma totalidade histórica, um exercício sempre complexo pelo menos no plano conceitual, ainda mais naquele histórico.

No entanto, Araguaia vai além de Araguaia. Testemunham essa força simbólica, e de certo modo vicária suplementar, fatos recentes, mas que colocaram Araguaia na cena de uma visibilidade máxima e problemática, justamente porque articulada a partir de muitas faltas, omissões, apagamentos. Antes de tudo a sentença de 24 de novembro de 2010, notificada ao governo do Brasil pela Corte Interamericana de Direitos Humanos (caso Gomes Lund e outros - Guerrilha do Araguaia - versus Brasil). Na sentença, o tribunal conclui que o Brasil é responsável pela desaparição forçada de 62 pessoas, ocorrida entre os anos de 1972 e 1974, na região do Araguaia. A corte também sancionou

\footnotetext{
${ }^{1}$ Doutor em Estudos Portugueses e Brasileiros e professor associado de Estudos Portugueses e Brasileiros da Universidade de Bolonha, Bolonha, Itália. E-mail: rvecchi@tlingue.unibo.it

${ }^{2}$ Este texto foi, em algumas de suas partes, discutido por ocasiões de debates sobre a ditadura militar brasileira, na Europa e no Brasil. Agradeço a Jaime Ginzburg, Ettore Finazzi-Agrò, Raul Antelo, Maria Lúcia de Barros Camargo, Eduardo Schmidt Capela, Francisco Foot Hardman e Maria Betânia Amoroso pelas observações instigantes sobre o tema.
} 
que as disposições da Lei da Anistia que impedem a investigação de graves violações de direitos humanos carecem de efeitos jurídicos. Depois, em março de 2012, o Ministério Público Federal assinou uma denúncia contra o coronel da reserva do Exército do Brasil, Sebastião Curió Rodrigues de Moura, suspeito de ser o autor do sequestro de cinco militantes capturados durante a repressão à guerrilha. Curioso notar que Sebastião Curió, oficial que se mudou para o sul da Amazônia para coordenar a repressão contra a guerrilha, ficou tão popular na região, sobretudo como coordenador do garimpo da Serra Pelada, que se tornou epônimo de uma cidade de quase 20 mil habitantes que foi intitulada Curionópolis (como evidencia um belo livro de Leôncio Nossa, Mata! O maior Curió e as guerrilhas no Araguaia). Indícios todos, estes, que mostram uma complexidade específica do contexto do Araguaia que parece se inscrever, contrariamente ao valor historicamente exemplar acima mencionado, em figuras intransitivas ou irredutíveis para conotar o espírito de um tempo.

De fato, inúmeras são as exceções que constituem a tentativa revolucionária do Araguaia, antes de tudo a sua problematicidade em encontrar um nome próprio na cena histórica da ditadura militar brasileira, em que parece surgir sempre como um hiato, um parêntese. É suficiente ver como, no volume de certo modo oficial Direito à memória $e$ à verdade, elaborado pela Comissão Especial sobre os Mortos e Desaparecidos Políticos, e publicado pela Secretaria Especial dos Direitos Humanos da Presidência da República, Araguaia é introduzida como uma "suspensão" da sequência cronológica que pauta o volume (Brasil, 2007, p. 195).

Além disso, singular era a trajetória do PCdoB (Partido Comunista do Brasil, que surgiu de um racha do Partido Comunista Brasileiro em 1962), que defendia a luta armada já antes da ditadura militar. Não secundou nem o foquismo, considerado excessivamente voluntarista, nem o projeto de revolução continental, que era avaliado como externo aos valores do marxismo-leninismo. Afastara-se tanto de Cuba como de Moscou e, depois de uma breve estação de cooperação militar através do treinamento de militantes, também da China, para se aproximar da experiência isolada de um socialismo europeu de molde stalinista, como o albanês (Gaspari, 2002, p. 408-409).

Mas as singularidades não acabam aqui e, pelo contrário, redundam: num quadro dominado pela guerrilha urbana, mas que encontrava na 
Amazônia uma declinação própria (também com outros movimentos, como ALN, VAR Palmares, ainda que com planos só esboçados, presentes no campo), o PCdoB teve a persistência de promover, a partir de 1966, uma invisível ocupação da região chamada de Bico do Papagaio, na divisa entre Maranhão, Pará e Tocantins, marcada por agudos conflitos por questões de terra, que se estenderam até 1974, deflagrando, a partir de 1972, um conflito de guerrilha planejado como detonador de uma guerra popular.

Isolada e persistente, a guerrilha do Araguaia se enraizou profundamente no contexto comunitário da região, criando laços com os habitantes que aprenderam a conviver com "os paulistas" ou o "povo da mata", paulistas oriundos predominantemente da classe média urbana em larga parte das filas do movimento estudantil (Brasil, 2007, p. 195). O exército desencadeou uma das mais ferozes repressões, com três expedições que chegaram a mobilizar, ao que parece, de 3 a 5 mil soldados que a partir de 1972, por quase dois anos, se lançaram sobre os grupos de guerrilha. Até o número das vítimas que foram executadas e eliminadas na guerrilha do Araguaia continua oscilante. A Comissão Especial analisou 64 casos de desaparecidos (Brasil, 2007, p. 203), 59 militantes do PCdoB (Gaspari, 2002, p. 461) e um número variável de moradores da região que apoiavam a luta. As vítimas poderiam ser - de acordo com a insuficiência documentária do caso que continua sendo objeto, inclusive depois do fim do regime militar, de uma macroscópica damnatio memoriae - em número bastante mais alto e, quase com certeza, não determinável. No entanto, esse caso aparentemente isolado do contexto das ações de resistência à ditadura concentra em si praticamente a metade do número de desaparecidos políticos (seriam 136, cf. Brasil, 2007, p. 17) dos anos do autoritarismo militar.

Mais uma singularidade do Araguaia: as caravanas dos familiares que já em 1980, ainda em tempos do regime militar, foram à região para recolher informações sobre os parentes desaparecidos apurando que havia indícios de uma vala clandestina e sinais de enterramento das vítimas dos massacres. Em seguida, sobretudo a partir dos anos 90, se sucederam missões de peritos forenses para localizar os restos mortais dos militantes mortos. Até agora foram resgatados os restos mortais só de dois militantes, Maria Lúcia Petit, em 1996, e Bergson Gurjão Farias, em 2009.

O que se executou de fato, sobretudo a partir da segunda fase da repressão, a começar de outubro de 1973, foi um massacre deliberado e 
irrestrito: a partir desse momento, não há sobreviventes ou presos, todos os integrantes dos grupos de guerrilha são mortos, e os seus cadáveres ocultados. Como observa Elio Gaspari:

A ditadura fixara um padrão de conduta. Fazia prisioneiros, mas não entregava cadáveres. Jamais reconheceria que existissem. Quem morria, sumia. Esse comportamento não pode ser atribuído às dificuldades logísticas da região, pois a tropa operava de acordo com uma instrução escrita: “Os PG (prisioneiros de guerra) falecidos deverão ser sepultados em cemitério escolhido e comunicado. Deverão ser tomados os elementos de identificação (impressões digitais e fotografia)" (Gaspari, 2002, p. 420).

Houve, portanto, um duplo ocultamento dos corpos dos inimigos mortos e dos arquivos que documentavam a violência da repressão praticada pelos militares que ficou assim, literalmente, obscena e não relatável. Em certo sentido, no quadro comparativo deste artigo, poderia surgir um traço de aproximação da estratégia de ocultamento do Araguaia com a guerra colonial de Portugal na África, submetida a um recalcamento análogo e com técnicas de certo modo comuns.

Araguaia, na verdade, acaba por se tornar a brecha que deixa entrever o rosto do horror do regime, em que a produção tanatopolítica que se articulou pela morte, a destruição e o ocultamento do corpo do inimigo é fruto de uma deliberada racionalidade.

Sendo assim, porém, as exceções do Araguaia se inscreveriam dentro de uma linha de continuidade com muitos outros contextos latinoamericanos posteriores. Na verdade, há uma densidade semiótica consistente no "texto" do Araguaia, que transcende de certo modo os fatos e talvez possa explicar o seu potencial de simbolização de uma violência de Estado que se abateu em vários âmbitos do contexto histórico brasileiro da época ou também em outras épocas da repressão dos movimentos populares no Brasil. Um traço, este, que confirma a modernidade da catástrofe da desaparição forçada, assim como a formula o sociólogo Gabriel Gatti (2008, p. 32). Vamos mencionar pela ocasião, ainda que sinoticamente, alguns, inclusive para sublinhar como aqueles que podemos entender como "subtextos" da cena do Araguaia resumíveis em três campos dominantes: culto, citação e barbárie abrem o terreno para uma aproximação como aqui se propõe do massacre do Araguaia como um objeto criticamente denso para uma contraleitura da cena autoritária brasileira. 
O primeiro elemento, na verdade uma conjetura, diz respeito ao fato de que os túmulos secretos dos guerrilheiros foram deslocados ao longo das décadas que seguiram a matança, o que é coerente com o objetivo do apagamento ou encobrimento dos eventos. Mas é interessante lembrar que, como aparece em depoimentos posteriores, por ordens superiores, corpos de militantes da guerrilha do Araguaia, enterrados na mata, foram retirados das covas e levados para outros locais para evitar "romarias da população" (Michael, 2004, p. A6). Essa troca de túmulos mostra o quanto o exército se ocupava para que os mortos não se tornassem objeto de culto por parte da população, que a ação revolucionária e o apoio em prol da população não fossem mitologizáveis pelo sentimento e a fé populares.

O segundo elemento se refere a outro suplemento simbólico que se inscreve como mais um "subtexto" no Araguaia: a barbárie da decapitação dos inimigos mortos, que remete para outra cena de massacre como a destruição de Canudos relatada por Euclides da Cunha em Os Sertões, assim como as narrativas de destruição da unidade figural, corpórea do inimigo do período colonial ou das lutas contra os jagunços inclusive em tempos republicanos. Evoca, como um recuo temporal, a violência da colonização ou da colonialidade: o corpo massacrado, ou despedaçado, minado na sua inviolabilidade que é o estatuto ontológico do humano; encontra em suma na figura mitológica da Medusa, na cabeça cortada, talvez o seu emblema mais eloquente do horror como abismo que flagra e silencia a representação (Cavarero, 2007, p. 15). Ao mesmo tempo, esse "subtexto" se articula pela acumulação de outros elementos, como a exibição do corpo do inimigo morto: é o que ocorre, por exemplo, com uma das lideranças pioneira da guerrilha, Osvaldo Orlando Costa, conhecido como Osvaldão, morto em fevereiro de 1974 e depois içado por um helicóptero, de modo que as populações da região pudessem ver o seu cadáver macabramente exibido. Também nesse caso, antes de enterrá-lo, lhe foi cortada a cabeça (Gaspari, 2002, p. 406). Uma imagem, certo, mas a imago mortis do inimigo, os vestígios dos seus restos, que remete para representações capazes, como sugere Giovanni De Luna estudando as fotografias dos cadáveres da guerra, de desmontar e repensar as retóricas monumentalizadoras que se acumulam em torno dos fatos bélicos (De Luna, 2006, p. 7).

Enfim, há outro elemento subtextual que proporciona, porém, a evidência de que o Araguaia funciona como uma narrativa complexa e 
simbólica da violência do autoritarismo, que com ferramentas interpretativas adequadas deve ser repensado. É o traço, que foi evidenciado por Edgar de Decca, de como as narrativas de massacre de certo modo se citam e criam, pelo menos na cena da violência de Estado histórica no Brasil, inesperadas conexões, semanticamente relevantes, como no caso de outro massacre, o de Eldorado dos Carajás contra camponeses do Movimento dos Sem Terra que ocorreu numa região próxima do Araguaia em 1996. A narrativa desse massacre mobilizou tanto a memória coletiva que, como nota o historiador, "menos de um mês depois deste massacre foi identificada uma guerrilheira assassinada no Araguaia pelo regime militar (Decca, 1997, p. 58). A deslocação, a repetição das narrativas (e, como já lembramos, temos na literatura brasileira uma das grandes obras que não é só uma escrita da violência mas é efetivamente uma narrativa de massacre, a de Euclides da Cunha) tem como consequência a de revelar a representação do massacre, embora isso implique os riscos de distorcer os fatos - portanto impedir a sua historicização, a sua citabilidade como história encerrada - pela superposição de filtros, de véus, de mediações. Funcionaria assim como uma espécie de restituição só e parcialmente simbólica mas que, pelo mecanismo da citabilidade, da re-citação, vai formar uma trama precária mas que debilmente proporciona representação de fatos que de outro modo ficariam indizíveis.

Aqui chegamos, a meu ver, ao ponto crucial que mostra a dimensão "exemplar", em termos teóricos, do Araguaia dentro do contexto de historicização ainda em aberto dos anos da violência do regime militar que dominou o Brasil de 1964 a 1985. A Corte Interamericana de Direitos Humanos, na demanda de 2009 que originará a sentença do ano seguinte, desenvolve algumas importantes considerações de ordem conceitual sobre os temas da restituição e reparação dos danos provocados pelo Estado na repressão do Araguaia. Afirma nos artigos 228 e 244, no âmbito da obrigação de reparar:

A reparação do dano ocasionada pela infração de uma obrigação internacional requer, sempre que seja possível, a plena restituição (restitutio in integrum), a qual consiste no restabelecimento da situação anterior à violação. [...] Em atenção ao tempo transcorrido, assim como à natureza e magnitude dos danos ocasionados, a Comissão considera, no presente caso, que não é possível que haja uma restituição plena. O elenco de medidas de reparações solicitadas considerará esta conclusão (OEA, 2009). 
A restituição, juridicamente definida, seria, portanto, como é evidente, impossível no caso do Araguaia. Ou seja, a restituição, assim formulada, também entraria naquele léxico negativo de que fala Derrida quando aborda o tema da impossibilidade do perdão recuperando as razões sobre o imprescritível de Jankélevitch, léxico que se refere ao ser passado que não passa (Derrida, 2004, p. 51): termos como irreparável, inapagável, irremediável, irreversível, inesquecível, irrevocável, inexpiável. Mesmo que ocupem áreas semânticas limítrofes, mas não coincidentes, nessa constelação terminológica se inscreveria também a impossibilidade de uma restituição, o "irrestituível", diríamos, do Araguaia.

O problema da restituição talvez represente, no plano conceitual, o campo mais problemático e ao mesmo tempo central da elaboração pósautoritária que se associa à violência da ditadura militar no Brasil. Não só porque o campo intersecta inúmeros saberes (direito, psicanálise, crítica literária e cultural, filosofia política, entre outros) mas também porque um dos marcos do terror de Estado praticado no século XX no subcontinente - com a destruição total do corpo do inimigo morto e ocultamento de seus rastros -, de que o Brasil foi um dos primeiros terrenos empíricos, põe drasticamente em crise e faz colapsar a noção jurídica de restituição ad integrum que é projetada no plano da impossibilidade ou das possibilidades exclusivamente fantasmáticas.

Como pode então a restituição ser entendida? O conceito de restitutio ad integrum pertence a uma das mais antigas tutelas, já prescrita pelo direito romano, de acordo com a qual se restabelece um status quo antes que foi modificado de modo ilegítimo. Pertence aos poderes extraordinários do Praetor, que podia exercê-lo também em nome de ausentes, menores ou incapacitados (Santí, 2005, p. 88). Fora do contexto estritamente jurídico, é oportuno lembrar o debate que na década de 90 ocorreu nos estudos latino-americanos, em particular pela contribuição de críticos como Enrico Mario Santí ou Alberto Moreiras, sobre o conceito de latino-americanismo e que desenvolviam uma reflexão sutil sobre a restituição. Na reconstrução de Santí em particular, o conceito de restituição é reformulado de modo particularmente interessante. Decorre da etimologia jurídica e dos seus reusos históricos, mas logo toma uma direção própria, dialogando com a ideia de "poéticas da restituição" sugerida por Geoffrey Hartman em The Philomela Project, o projeto virado para o restauro ("restoration") das vozes das pessoas que não podem falar ("inarticulate") (Hartman, 1991, p. 169). Perspectiva 
interessante, esta do crítico americano, porque de certo modo se conecta com o debate sobre a possibilidade de "fala" dos subalternos que, nesses mesmos anos, a partir de um famoso ensaio de Spivak, alimenta uma discussão não menos intensa.

Hartman (1991, p. 170-174) capta que o processo de restituição, entre presenças e ausências, é inexaurível ("o processo de restituição, de corrigir os erros, parece sem fim") e, sobretudo, o projeta no campo político, da subjetividade ética ("a new, spiritually as well as politically effective, respect"). Dentro desta visão que recorta "ficções legais" de acordo com as quais os historiadores criam personagens para as presenças-ausências do passado, Santí (1992, p. 89) tende a valorizar as "hermenêuticas compensatórias" das perdas da restituição, discutindo quais figuras são criadas para preencher as ausências implícitas nas poéticas restitutivas e elaborando a hipótese de que a restituição como prática crítica sempre é suplementar, visto que compensa lacunas anteriores, portanto excede - mais do que restaura - um original que definitivamente se perdeu e se dissolveu. $\mathrm{O}$ gesto crítico da restituição, desse ponto de vista, seria, portanto, sempre mais amplo em relação ao que se entende restituir, porque, preenchendo um vazio, se investiria sempre mais força (embora, pelos ocos e faltas, a força necessária seja imensurável) ou até se modificaria o objeto.

O problema da restituição, na reconceitualização latino-americanista, perante as vozes mudas, passa desse modo para a parte do intérprete e não fica do lado do objeto que, aliás, é, na maioria dos casos, fragmentário ou perdido. Dentro de uma perspectiva como essa, o que prevalece é o interesse por como a restituição ocorre, não tanto pelo que ela pode resgatar. Nesse sentido, surge uma questão próxima daquela levantada pelos estudos subalternos: a restituição, na sua tensão com outro termo afim, mas não coincidente, como é restauro ("restoration"), coloca o problema não poético, mas político do intérprete que fala "em nome de" ou de quem fala efetivamente "do ponto de vista do outro" (Santí, 2005, p. 13 e p. 18), sobrepondo a própria voz com a voz do outro. Assim, a ideia da restituição que incorporaria, como anota Alberto Moreiras, uma espécie de "surplus economy" (Moreiras, 2001, p. 154) elucida adequadamente a filologia como prática hermenêutica correlativa que põe a questão de como ler um texto (ou um passado) degradado e lacunoso, sem o trair, sem o transformar, pelo gesto da 
restituição não criticamente formulado ou praticado enquanto restauro, num texto contemporâneo e irredutivelmente outro.

Perante o dilema de uma restituição juridicamente impossível ou filologicamente arriscada, ao mesmo tempo vale a pena não abdicar da ideia de uma restituição do texto do Araguaia que restaure integralmente a voz das vítimas silenciadas dos massacres. Como já Gramsci tinha assinalado num texto seminal, sempre para a configuração epistemológica dos estudos subalternos, a história "desagregada e episódica" dos grupos sociais subalternos, praticamente desprovida de rastro histórico, pode ser recuperada através de um exercício criador e metódico (uma restituição, de certo modo) de investigação que aproveita indícios débeis e dispersos, escapados à intenção autoral, para construir histórias alternativas do ponto de vista não dominante (Gramsci, 1975, p. 2283).

No caso do Araguaia, o resgate de uma narrativa efetivamente restitutiva passa por uma incorporação das exceções e dos subtextos que tornam a superfície simbólica do caso extremamente intricada, constituída de uma trama densa e até hoje só obliquamente decifrável. Se por um lado não há e não haverá uma "escrita do massacre" do Araguaia como ocorreu, como regime de exceção, em Canudos, ao mesmo tempo, pelas suas peculiaridades, o Araguaia resume exemplarmente experiências históricas de violências políticas que marcaram não só o Brasil mas também outros países sul-americanos. O texto que, pelo momento, prevalece é o silêncio imposto pelo regime militar. Este também entra no processo de restituição, porque o modo como se produziu o Araguaia permite definir uma sintaxe simbólica do massacre, que assim se torna, entre ouras coisas, também uma técnica para "imaginar a comunidade", uma narrativa identitária com a obra, o extermínio, que repete e se repete na diferença das performances pense-se na cena da tortura ou de outros contextos repressivos do tempo - que agem sobre os corpos do inimigo.

O Araguaia como texto, como narração impossível, ou interrupções conjugadas preenchendo ficticiamente um vácuo, um oco, põe o problema do texto da desaparição política. Não no sentido de uma relação direta entre a desaparição da história (Araguaia) e a escrita da desaparição do corpo do inimigo político. Mas porque o ocultamento decorre de uma matriz comum, não só de ordem histórica, mas especificamente conceitual, como produto de uma razão semiótica que 
impossibilita ou pelo menos mina a possibilidade da narrativa pelo apagamento, a destruição lucidamente construída do signo. Por isso, o Araguaia pode ser assumido como palimpsesto crítico para talvez viabilizar uma leitura de textos (de obras) da desaparição política engendrada pela mesma violência autoritária que produziu o Araguaia como "obra".

O tema atravessa pelo menos liminarmente numerosos outros textos, perpassa pela literatura memorialista produzida na urgência da abertura política, ou aparece em grandes romances como Sempreviva, de Antonio Callado (1981), em que a quête alucinada de Quinho, o protagonista, exilado e regressado clandestinamente para o Brasil, é originada pela desaparição e morte da companheira, a busca de outras duas guerrilheiras e a localização dos autores das atrocidades daquele tempo: a flor do título metaforiza a condição do luto irresolvível quando falta o corpo, a sua impossível fetichização mesmo como representação fetichizada ou delírio, e se naturaliza na figura da flor mortuária das "saudades perpétuas".

Na construção de uma escrita que da história mutilada (Araguaia) abra um espaço - na verdade um limiar - na literatura, há uma obra que enreda muitas das questões de um "texto", uma obra semiótica paradoxal, do Araguaia. Trata-se do romance de Bernardo Kucinski K., de outubro de 2011, contemporâneo da Comissão Nacional da Verdade e que na véspera dos 50 anos do golpe de estado militar inaugura uma possibilidade efetiva de escrever a desaparição política. Como um apêndice paradoxal do caso do Araguaia.

O título que remete de imediato para o labirinto distópico da narrativa kafkiana expõe logo a literariedade do projeto. Embora seja fácil pensar que a articulação se constrói sobre a substância biográfica do autor, irmão de um dos desaparecidos pela repressão política em 1974, Ana Rosa Kucinski, professora de química na USP, que com o marido Wilson Silva foi sequestrada e eliminada (as fotos de Ana Rosa apareceram, em São Paulo, na mostra Ausências, do fotografo argentino Gustavo Germano, em que se destacava o mesmo pano de fundo, o antes e o depois, o então e o agora: obra também que põe em jogo o problema conceitual da crítica pela ausência da presença, no caso da desaparição).

O livro foge à armadilha memorialista e se envereda pelo caminho da invenção: como na primeira linha da carta inicial ao leitor se postula: "Tudo neste livro é invenção, mas quase tudo aconteceu" (Kucinski, 
2011, p. 13). O laço pessoal portanto não tange a substância da narração, para deixar espaço ao outro, imenso espaço privado constituído pela invenção de K., o pai de Ana Rosa (não nomeada na narrativa). A economia da ausência enquanto material se desdobra a partir de uma ideia de acumulação, de recolha de histórias, fragmentos, contos como se uma possível homogeneidade narrativa não só fosse inviável mas mesmo que tentada desmoronasse nos restos de qualquer unidade ideal, sob o impacto fraturante da experiência traumática.

Essa acumulação de fragmentos não se submete a uma ordem que seria artificial, deixando margem a multíplices leituras ainda que dentro da moldura tênue de uma série mínima: como sempre se sanciona na carta ao leitor: "A unidade se deu através de K. Por isso, o fragmento que o introduz inicia o conjunto, logo após a abertura. E o que encerra suas atribulações está quase no final. A ordem dos demais fragmentos é arbitrária, apenas uma entre as várias possibilidades de ordenamento dos textos" (Kucinski, 2011, p. 13).

Assim, o romance parece desfazer-se na arquitetura mais precária mas, ao mesmo tempo, muito mais densa, pela força das relações e das elipses - de uma antologia de contos (Flávio Aguiar) em que o gesto do autor se sobrepõe mais ao de um organizador de um conjunto de parte desunidas, expondo a parcialidade e a ruptura.

K. é o judeu polonês da resistência emigrado no Brasil, escritor yiddish, que percebe, no momento do sumiço e da angústia crescente pela subtração definitiva, que desconhece a filha e o mundo que ela tinha construído. A quête nesse sentido é dupla, por um lado das notícias dela - se continua ou não em vida -, por outro dos rastros que ainda que de forma dolorida a reaproximem dele, um exercício cultual e póstumo dos sinais que ela espalhara na existência, num engajamento com o mundo que tinha passado completamente despercebido pelas distâncias e distrações de K. No entanto, apesar dos esforços, da corja de corruptos e falsos ajudantes que alimentam esperanças irreais, a restituição ad integrum é impossível, mas outras formas restitutivas se delineiam como resultado de um trabalho suplementar, do preenchimento de objetos que se perderam para sempre. Poder-se-ia pensar que pela figuração literária tal processo recompositivo ocorre. Mas assim seria um postiço, um fetiche de algo que deixou de ser pela violência enorme que se abateu sobre ele. No entanto, o que se torna 
evidente é que o gesto da restituição é um gesto de autor (praetor), que ocorre pelo próprio repúdio da arte e de outras formas cultuais.

O que ocorre com K. é uma iniciação através de algumas dilacerações: o abandono da literatura (que não encontra palavras que expressem a indizibilidade do trauma), o abandono da religião (da comunidade hebraica, que, pela ausência do corpo, recusa uma matzeivá simbólica), o abandono do livro (pelo tipógrafo que lhe nega esse enterro figurado porque o considera subversivo), o abandono de uma sociedade, de um país que, insensível aos horrores, monumentaliza a memórias dos algozes e não das vítimas.

A iniciação que funciona como uma "verdadeira simulação" (Baudrillard, 1988, p. 23) pela força do traumatismo estético da experiência histórica proporciona outro elemento suplementar: através do tropo da prosopopeia, ou seja, do objeto inanimado, que tem nome e fala, figuras abjetas da repressão como Sérgio Paranhos Fleury, o delegado coordenador do DOPS e todo o grupo de algozes paulista, encontram, enquanto máscaras, rostos, atos e palavras do horror em alguns fragmentos impressionantes.

K., assim, assume sua função suplementar e parcial em relação a um resgate do passado, mas se trata da maior recomposição possível, se configura como uma "poética da restituição" no sentido de Geoffrey Hartman, que no entanto, ao deixar emergirem despojos de um passado recalcado, aciona um dispositivo de reparação, como se depreende na denúncia não dos responsáveis dos crimes mas da sociedade que os treinou e os protegeu e que ainda conserva ativa, apesar de temporariamente não em função, a máquina efetiva e não só ideológica que tornou possível, num passado recente, a prática da violência de estado contra cidadãos inermes cuja destruição foi lucidamente planejada.

Como o Araguaia, enquanto texto, K., que não poupa críticas e denúncias a 360 graus e constrói uma ideia alternativa de patrimônio (um patrimônio que com Aby Warburg se pode chamar de patrimônio de sofrimento), narrativizando rastros e sinais que assim podem criar uma outra narração do passado dentro de uma poética restitutiva próxima, por morfologia e conteúdo de uma demanda de reparação a partir de um uso poético muito cuidadoso das ausências que são o legado da época autoritária.

$\mathrm{O}$ que se depreende destes casos textuais (Araguaia e K), também pela sanção prevista pelo dispositivo da demanda citada anteriormente, é 
de certo modo a simetria inclusive, mais uma vez etimológica, que combina "reparar" e "restituir", este na acepção filológica que estamos discutindo: ambos com um prefixo recursivo, o primeiro termo é um composto do verbo latim "parare" no sentido de dispor, o segundo do verbo "statuere" que significa fazer com que algo (que foi posto ou disposto) fique estável e firme. Um sentido que, ainda que só no plano linguístico, mas com projeções também naquele conceitual, pauta as relações entre reparação e restituição mostrando uma conexão que os encadeia (numa ordem menos esperada) e os põe numa relação funcional.

O que a restituição do texto do Araguaia ou de Ana Rosa Kucinski põe de certo modo em jogo é uma filologia, por assim dizer, das ausências a partir das quais procura depreender não tanto uma verdade do texto (que fica ancorada à circunstância ou à ideologia), mas o seu significado como resultado da sua sintaxe linguística (Santí, 2005, p. 89). Nessa linha, seria preciso definir as técnicas que deveriam ser aplicadas, filologicamente, ao texto lacunoso dessa página de história. Dentro de um repertório amplo e largamente interdisciplinar, se podem mencionar exemplos como a gramatologia de Derrida, que, pela lógica do suplemento, propõe tornar a presença o rastro do que não está, da ausência, ou, no campo das artes plásticas, a obra de Christian Boltanski, que também se concentra sobre a presença de uma ausência, ou a sua visibilidade, como acontece na obra La maison manquante (Assmann, 2002, p. 415).

A restituição exige, portanto, complexas operações críticas, inclusive epistemológicas, sobre como, a partir da sua insuficiência e ao mesmo tempo porosidade, pode contribuir a alimentar um trabalho, enlutado e residual, de outro modo impossível, sobretudo na ausência dos despojos ou de restos materiais. Desse modo, se redefinem as práticas, efetivas e simbólicas, de restituição (em relação também com outras práticas culturais e cultuais, como o restauro, a reintegração, o resgate ou a inviabilidade da própria ideia jurídica de restitutio ad integrum). No âmbito dos estudos latino-americanos, políticas conceituais metaforicamente conexas com a responsabilidade "filológica" da restituição textual se diferenciaram, por exemplo, do trabalho de restauração impossível de algo que definitivamente se perdeu, porque exibem um excesso ou um suplemento em relação ao objeto que as origina. Assim é possível referenciar o texto sobre a violência da ditadura militar no Araguaia como um esforço político de vocalização 
dos silêncios do passado, portanto da abertura de campo para outra poética de restituição.

A possibilidade de escrever outra narrativa passa, no entanto, pelo desocultamento do passado, no sentido da localização de despojos e da abertura dos arquivos do exército, ou seja, por uma reparaçãorestituição, hoje, essencialmente documentária. Porque, como afirma a sentença de 24 de novembro de 2010, sobre o Araguaia, o "Estado deve continuar desenvolvendo as iniciativas de busca, sistematização e publicação de toda a informação sobre a Guerrilha do Araguaia, assim como da informação relativa a violações de direitos humanos ocorridas durante o regime militar" (Corte Interamericana de Direitos Humanos, 2010, XXII, 16). Tal atitude marca o fato de que, pela primeira vez, uma sentença internacional reconhece que, para as vítimas e as suas famílias, o direito à informação deve ser considerado por si mesmo um dos direitos humanos a serem reconhecidos.

Assim, em nome de um "direito humano à verdade", os textos das desaparições políticas poderiam ser restituídos, apesar de suas lacunas ou faltas, sobretudo na impossibilidade de uma escrita integral dos massacres que se consumaram durante a ditadura, como fato racional, sistematicamente ocultado pela ditadura, que procurou apagar todos os seus vestígios materiais. Por paradoxo, no entanto, o Araguaia, pela sua força simbólica enquanto palimpsesto não inteiramente apagado, mas encoberto ainda por outra voz dominante, poderia reemergir como outra escrita, proporcionando uma narrativa exemplarmente reveladora de outras violências do Estado, nos anos ainda bastante sombrios da ditadura militar. Mais do que qualquer monumento, a sua possibilidade de ser citada enquanto narrativa torna a sua restituição, ainda que parcial ou marcada pelos riscos de expressar tempos outros e não o tempo próprio, um ato obrigatório e não secundário para a fundação de uma memória comunitária também dos anos obscenos e mudos, pelo menos do ponto de vista das vítimas, do horror.

\section{Referências}

ANDRADE, Carlos Drummond de (1983). Poesia e prosa organizada pelo autor. 5. ed. Rio de Janeiro: Nova Aguilar. 
ASSMANN, Aleida (2002). Ricordare: Forme e mutamenti della memoria culturale. Bologna: Il Mulino.

BAUDRILLARD, Jean (1988). La sparizione dell'arte. Tradução para o italiano de Elio Grazioli. Milano: Politi.

BRASIL. Secretaria Especial dos Direitos Humanos da Presidência da República (2007). Direito à memória e à verdade. Elaborado pela Comissão Especial sobre os Mortos e Desaparecidos Políticos. Brasília: SDH/PR.

CAVARERO, Adriana (2007). Orrorismo ovvero della violenza sull'inerme. Milano: Feltrinelli.

DECCA, Edgar Salvadori de (1997). Quaresma: um relato de massacre republicano. Anos 90, Porto Alegre, v. 5, n. 8, p. 45-61.

DERRIDA, Jacques (2004). Perdonare. Milano: Raffaello Cortina.

DE LUNA, Giovanni (2006). Il corpo del nemico ucciso. Violenza e morte nella guerra contemporánea. Torino: Einaudi.

GASPARI, Elio (2002). A ditadura escancarada. São Paulo: Companhia das Letras.

GATTI, Gabriel (2008). El detenido desaparecido. Narrativas posibles para una catástrofe de la identidad. Montevideo: Trilce.

GRAMSCI, Antonio (1975). Ai margini della storia (storia dei gruppi sociali subalterni). Quaderno 25 (XXIII) 1934. In: Quaderni del Carcere. Edição organizada por Valentino Gerratana. Vol. 3. Torino: Einaudi.

HARTMAN, Geoffrey H. (1991). The Philomela Project. In: Minor prophecies. The literary essay in the culture wars. Cambridge, London: Harvard University Press.

KUCINSKI, Bernardo (2011). K. São Paulo: Expressão Popular.

MICHAEL, Andréa (2004). Exército transferiu os corpos de guerrilheiros do Araguaia. Folha de S. Paulo, São Paulo, 7 mar. Caderno Brasil, p. A3.

MOREIRAS, Alberto (2001). The exhaustion of difference. The politics of Latin American cultural studies. Durham: Duke University Press.

OEA (2009). Demanda perante a Corte Interamericana de Direitos Humanos. Caso 11.552 - Julia Gomes Lund e outros (Guerrilha do Araguaia). Contra a República Federativa do Brasil. Disponível em: <http:/ / www.cidh.oas.org/demandas/11.552\%20Guerrilha\%20do\%20Araguai a\%20Brasil\%2026mar09\%20PORT.pdf>. Acesso em: 10 mar. 2014.

CORTE INTERAMERICANA DE DIREITOS HUMANOS (2010). Sentença de 24 de novembro. Caso Gomes Lund e outros (Guerrilha do Araguaia) vs. Brasil. 
Disponível

em:

<http:/ / www.corteidh.or.cr/docs/casos/articulos/seriec_219_por.pdf>.

Acesso em: 10 mar. 2014.

SANTÍ, Enrico Mario (1992). Latinamericanism and restitution. Latin American literary review, Chicago, v. 20, n. 40, p. 88-96.

(2005). Sor Juana, Octavio Paz, and poetics of restitution. In: Ciphers of History. Latin American readings for a cultural age. New York, Basingstoke: Palgrave Macmillan.

Recebido em dezembro de 2013.

Aprovado em fevereiro de 2014.

\section{resumolabstract}

\section{O passado subtraído da desaparição forçada: Araguaia como palimpsesto}

Roberto Vecchi

O artigo aborda o tema da desaparição forçada no contexto do autoritarismo militar no Brasil definindo em primeiro lugar o caráter problemático da restituição de uma memória dos desaparecidos a partir da inviabilidade da categoria jurídica de restitutio ad integrum. O palimpsesto histórico a ser pensado nesta perspectiva é aquele da guerrilha do Araguaia, que foi apagada dos mapas da história do Brasil. O caso leva à problematização do conceito de restituição dentro do debate contemporâneo que o aproxima do ato de autor e o reconfigura dentro de uma perspectiva de subjetividade ética, analogamente ao que acontece com outro conceito chave da contemporaneidade, aquele de testemunha. A literatura se presta assim a se tornar um fértil campo onde repensar a restituição. $\mathrm{O}$ caso literário aqui considerado é o romance $K$., de Bernardo Kucinski, que, assumindo explicitamente um pacto ficcional, consegue subtrair à destruição sem ruína da desaparição forçada uma memória precária mas possível do passado traumático.

Palavras-chave: ditadura, guerrilha do Araguaia, Bernardo Kucinski.

\section{The subtracted past of the forced disappearance: Araguaia as a palimpsest}

\section{Roberto Vecchi}

The article approaches the aporetic topic of the forced disappearance in the context of military authoritarianism in Brazil, primarily setting the problematic character of the restitution in the case of the political "desaparecidos" deriving 
from the impossibility of the legal category of "restitutio ad integrum". The historical palimpsest to be thought in this perspective is the case of the Guerrilla of Araguaia that was completely erased from the maps of the Brazilian history. The case opens the discussion on the concept of restitution in the contemporary theoretical debate. It is configured similar to the act of author, inscribed in a perspective of ethical subjectivity, similarly in this sense to what happens with another key concept of contemporaneity: the witness. Literature can be assumed in this perspective as a fertile field through which rethinking restitution. The literary case considered in the article is the novel K., by Bernardo Kucinki. Explicitly assuming a fictional pact, it makes possible to subtract - from a destruction without ruins - the precarious but possible memory of the traumatic past of the forced disappearance.

Keywords: dictatorship, Araguaia guerrilla, Bernardo Kucinski. 